\title{
João do Rio e a Alma encantadora das ruas: o lugar do subalterno e do cidadão em sua obra
}

\author{
Thiago Cardoso Franco ${ }^{1}$ \\ Maria Luiza Martins de Mendonça²
}

Recibido: 2014-07-25

Enviado a pares: 2014-07-28
Aprobado por pares: 2014-09-03

Aceptado: 2014-09-12

DOI: 10.5294/pacla.2015.18.2.6

Para citar este artículo / to reference this article / para citar este artigo

Franco, T.C., de Mendonça, M.L.M. Junio de 2015. João do Rio e a Alma encantadora das ruas: 0 lugar do subalterno e do cidadão em sua obra. Palabra clave 18(2), 452-474. DOI: 10.5294/pacla.2015.18.2.6

\section{Resumo}

O objetivo deste artigo é identificar se o subalterno tem espaço de fala na obra de João do Rio, precursor brasileiro da reportagem in loco e do jornalismo como profissão. Os objetos de análise são textos do começo do século XX, publicados no jornal Gazeta de Noticias, disponíveis no acervo da Biblioteca Nacional, e também a terceira obra publicada do cronista. Os objetivos específicos são: identificar o espaço do subalterno e o sentido de cidadão na obra do jornalista $A$ alma encantadora das ruas. Para a metodologia da análise do conteúdo, será utilizado o software Weft QDA, de base qualitativa.

\section{Palavras-chave}

Cidadão, subalterno, jornalismo (Fonte: Tesauro da Unesco).

1 Pós-doutorado em comunicação audiovisual na Universidad Autónoma de Barcelona. Universidade Federal de Goiás. Brasil. thiagofranco730@gmail.com

2 É mestrando do Programa de Pós-graduação em Comunicação, da Universidade Federal de Goiás-UFG. Brasil. mluisamendonca@gmail.com 


\section{João do Rio y El alma encantadora de las calles: el espacio del subalterno y del ciudadano en su obra}

\section{Resumen}

El objetivo de este trabajo es identificar si el subalterno tiene espacio de expresión en la obra de João do Rio, precursor brasileño del reportaje in loco y el periodismo como profesión. Los objetos de análisis son los textos de principios del siglo XX, publicados en el diario Gazeta de Noticias disponibles en la colección de la Biblioteca Nacional de Brasil y también la tercera obra publicada del cronista. Los objetivos específicos son: identificar el significado de la palabra ciudadano en el trabajo del periodista e identificar los espacios de las camadas subalternas en el tercer libro del autor, El alma encantadora de las calle ( $A$ alma encantadora das ruas). Para la metodología de análisis se utilizará un software llamado Weft QDA, con una base cualitativa.

\section{Palabras clave}

Ciudadano, subalterno, periodismo (Fuente: Tesauro de la Unesco). 


\section{João do Rio and The Charming Soul of the Streets: The Subaltern Space and Citizen in his Work}

\section{Abstract}

The aim of this study is to identify whether the subordinate has space for expression in the work of João do Rio, Brazil precursor and crazy story in journalism as a profession. The objects of analysis are the texts of the early twentieth century, published in the newspaper Gazeta de Noticias available in the collection from the National Library of Brazil and also the third published work by the chronicler. The specific objectives are: to identify the meaning of the word citizen in the journalist's work and identify the areas of the subordinate layers in the third book of the author, The charming soul of the streets (A alma encantadora de las calles). For the analysis, Weft QDA software, with a qualitative basis is used.

\section{Keywords}

Citizen, subordinate, journalism (Source: Unesco Thesaurus). 


\section{Introdução}

Entre a subida e a descida da tina fatal, eu os ouvia: O minério!

É o mais pesado de todos os trabalhos. Cada pedra pesa quilos. Depois de se lidar algum tempo com isso, sentem-se os pés e as mãos frios; e o sangue, quando a gente se corta, aparece amarelo... É a morte (Rio, 1904, p. 1).

O texto acima é parte da crônica social, publicada no jornal Gazeta de Noticias $^{3}$, no dia 22 de junho de 1904. O autor é João do Rio, célebre jornalista e escritor, conhecido por ouvir e reproduzir vozes da rua. Polêmico jornalista, precursor da reportagem in loco realizada em ambientes periféricos, marginais, viveu integralmente para e do jornalismo, chegando mesmo a montar sua própria empresa, o jornal $A$ Pátria. João do Rio ou João Paulo Alberto Coelho Barreto (assinava também como Paulo Barreto) nasceu em agosto de 1881, no meio de uma família sem muitos recursos materiais; começa ainda muito jovem a trabalhar em jornais para prover seu sustento, e seu estilo vai até mesmo levantar discussões sobre o entrelaçamento entre jornalismo e literatura.

Já o diário Gazeta de Noticias ficou conhecido pela popularidade, ou melhor, pelo "jornalismo barato, popular" mais bem acabado, expressão cunhada por José Veríssimo, ainda na virada do século XIX para o XX.

Em 1875 a Gazeta de Noticias, fundada pelo Dr. Ferreira de Araújo, que ainda a dirige hoje, e outros, inaugurou no Brasil o jornal barato, popular, livre de compromissos partidários ou semelhantes, e também 0 jornal fácil de fazer, sem systema na distribuição das matérias, à portugueza. Escriptores dos mais estimados, e realmente distinctos, do tempo, dando a sua collaboração à Gazeta a tornaram querida em todo o paiz, onde a sua grande liberdade de apreciações e conceitos, a sua veia espirituosa, a sua variedade e leveza a fizeram popular (Veríssimo, 1900, p. 41).

Conforme diz o texto de Veríssimo, o jornal era popular, feito por escritores renomados. Entretanto, João do Rio não foi o primeiro escritor considerado popular. Ribeiro (2004, p. 130) lembra que Artur Azevedo fez grande sucesso e por bastante tempo no jornal O País. A palavra popular,

3 O presente artigo preserva exatamente a construção da língua portuguesa usada na obra original. 
nesse contexto, deve ser pensada a partir de duas perspectivas: a que considera que, no período em que esses autores publicaram, apenas $5 \%$ da população tinham acesso à instrução pública na Capital (Rio de Janeiro). Assim, escritor popular (no discurso dos literatos dessa época) era quem conseguia atingir o máximo de pessoas desse reduzido universo populacional. Por outro ângulo, o popular também é visto de forma social-etnográfica, sendo o povo/popular aqui representado por sua pertença às camadas subalternas da sociedade, fato que João do Rio transportou para as páginas dos jornais aqueles ambientes mais "marginais e recônditos territórios da experiência urbana” (Ribeiro, 2004, p. 193).

Na história da literatura até sua época, Veríssimo (1915) titula vários escritores como populares. Entre eles estão: Frei Vicente [1564-1639], Domingos Caldas Barbosa [1740-1800], Martins Pena [1815-1848], Antônio Gonçalves Teixeira de Sousa [1812-1861], Gonçalves Dias [18231864], Joaquim Manuel de Macedo [1820-1882], Bernardo Guimarães [1825-1884], Laurindo Rabelo [1826-1864], Casimiro José Marques de Abreu [1839-1860].

Ao analisar o contexto de popular nos textos de Veríssimo (1900; 1915), nota-se que os sentidos estão relacionados à popularidade/conhecimento ou também a questões étnicas, cultura popular rural e urbana acima citadas.

A relação da literatura com o jornalismo não ocorre de imediato. Primeiro "o jornalismo político antecedeu o jornalismo literário o qual, por sua vez, cresceu juntamente com o jornalismo noticioso fundamentado em critérios discursivos internos e bases econômicas de auto-sustentação" ( Ribeiro, 2004, p. 118).

João do Rio era um dos pseudônimos usado no jornal Gazeta de Noticias. Ele se assumia como jornalista, tinha consciência das mudanças que estavam ocorrendo na cidade do Rio de Janeiro, como também no jornalismo, que passava do caráter individual para entrar de vez no formato comercial, no jornalismo moderno. 
Medina (1988, p. 54) lembra que João do Rio criou um problema para época: onde termina o jornalismo e começa a literatura? Ele mesmo comenta a intercessão das duas formas: "o jornalismo, em toda a parte, tem sido um fator de arte literária, e isto é razoável, quando o jornal tende a substituir o livro cada vez mais. Se é apressada, às vezes, tal literatura, lucra, por outro lado com a difusão" (Rio, 1994, p. 93).

A palavra apressada responde às críticas de José Veríssimo sobre o volume de obras que surgia na época sem o cuidado que a vida intelectual exigia. Uma crítica que atingia diretamente a forma de escrever do jornalista. Mas o repórter rebate dizendo que literatura apressada é "o aparecimento de jovens e ardentes aptidões literárias” (Rio, 1994, p. 87).

A pressa é o reflexo da velocidade moderna. João do Rio adorava a vida corrida, a técnica, a modernidade do cinema. Ele transformou suas crônicas em retratos velozes com textos que transpiravam movimento. Não por acaso, uma de suas colunas vem a se chamar Cinematógrapho.

Se, para José Veríssimo, a obra de Paulo Barreto não passa de lite-
ratura apressada, para Brito Broca, bem mais equilibrado no julga-
mento, o autor é, acima de tudo, o repórter, o cronista que se tornou
verdadeiro historiador de uma época. Mas para valorizar estes ângu-
los da produção de João do Rio, é preciso abandonar os instrumen-
tos críticos da análise literária e descobrir a contribuição jornalística.
Pelo menos num aspecto os autores não levantam controvérsias:
Paulo Barreto é o cronista e o repórter do 1900 no Rio de Janeiro,
centro dessa atividade no Brasil dessa época (Medina, 1988, p. 54).

Do ponto de vista literário, Alves (2009, p. 356) reforça que, mesmo de forma ligeira, sem engajamento político ou lucidez social militante, João do Rio até certo ponto abstraia a complexidade do mundo moderno. Ele conseguiu ressaltar as cidades e seu crescimento desordenado, plural, a miséria, a violência, a promiscuidade, a elegância, o refinamento, o dinheiro e a futilidade. Seria essa uma forma de possibilitar a expressão do subalterno? A proposta, aqui, é identificar até que ponto o subalterno tem espaço de fala na obra de João do Rio, com sua atenção para a diversidade social, e qual seria o sentido de cidadão na sua obra, nas crônicas e no seu livro $A$ alma encantadora das ruas. 
Medina (1988), a parir de um olhar jornalístico, aponta que há um problema na posição de quem fala. João do Rio se colocava como autor e não como repórter intermediário e impessoal. $\mathrm{O}$ jornalista em toda a obra se mostra egocêntrico, "o eu aparece de forma obcecante" (Medina, 1988, p. 62).

Mas, ao revelar uma parte da sociedade brasileira que, no mundo jornalístico, não leva nomes, legendas, caracteres ou identificações, pode-se supor que tenha propiciado visibilidade para seres periféricos, que viviam na miséria, bem como personagens da modernidade. $\mathrm{O}$ jornalista observa as práticas do mendigo, do operário, do bandido, entre outros, de indivíduos pertencentes às camadas subalternas da sociedade carioca. Talvez nesse ponto esteja a resposta que incomoda Cremilda Medina.

\begin{abstract}
Nem sempre ele é preciso na enquete em que todos os escritores ouvidos ou consultados por escritos são identificados. Na grande parte de suas reportagens, as fontes são personagens anônimos, caracterizados por uma presença mais ficcional do que jornalística, ou ficam semi-identificados como tipo sociais, sem perfeita individualização. É raro 0 caso em que as informações chegam à identificação direta (Medina, 1988, p. 61).
\end{abstract}

Ao ler João do Rio (2007) e também as colocações de Ribeiro (2004) e Medina (1988), está claro que o jornalista busca sua matéria-prima nas ruas do Rio de Janeiro. Para tentar responder a tais inquietações, é necessário delimitar o conceito de subalternidade aqui utilizado a partir dos escritos de Antônio Gramsci.

\title{
Recortes sobre hegemônicos e subalternos
}

Por enquanto, pode-se fixar dois grandes planos superestruturais: 0 que pode ser chamado de sociedade civil (isto é, o conjunto de organismos chamados comumente de privados) e 0 da sociedade política ou Estado, que correspondem à função de hegemonia que o grupo dominante exerce em toda a sociedade e àquela de domínio direto ou de comando, que se expressa no Estado e no governo jurídico. Estas funções são precisamente organizativas e conectivas. Os intelectuais são os comissários do grupo dominante para o exercício das funções subalternas da hegemonia social e do governo político (Gramsci, 2001, pp. 20-21). 
O conceito de hegemonia não nasce com Gramsci. Hoare e Sperber (2013, p. 94) lembram que a palavra deriva do grego antigo eghestai que significava conduzir/dirigir. Durante a Guerra do Peloponeso, a palavra passou a ser eghemon, uma referência às cidades mais pujantes, conquistadoras, populosas.

Hoje dentro de uma perspectiva das relações internacionais, a palavra hegemonia preserva, de certo modo, o sentido eghemon. Um Estado é hegemônico quando domina as forças militares, a diplomacia e, claro, se destaca no campo político ao mostrar domínio sobre outras nações.

Hoare e Sperber (2013) reforçam que o Gramsci usa a palavra não apenas em referência à posição vertical burguesia/operário = hegemonia/ subalterno. $\mathrm{O}$ autor compreende a hegemonia como toda ação política dominante conquistada por um grupo social, dentro de um curso histórico. Ainda é importante dizer que "Antonio Gramsci jamais forneceu uma definição precisa de hegemonia, capaz de ser válida uma vez por todas” ${ }^{4}$ (Hoare e Sperber, 2013, p. 95, tradução dos autores).

Da maneira como se concebe aqui, o termo subalterno se refere à posição que classes e grupos ocupam em uma determinada sociedade. A condição de subalternidade aplica-se não apenas às classes, mas também a grupos sociais numa clara indicação de que percebia a heterogeneidade das classes sociais. Por isso, a condição subalterna não se limita à posição ocupada nas relações de produção, mas estende-se para a esfera da cultura (subalterna) que abriga formas particulares de concepção da vida e do mundo, distintas das concepções oficiais, legitimadas, hegemônicas. O termo só pode ser compreendido em relação ao conceito de hegemonia que o autor descreve como a capacidade que as classes economicamente dominantes possuem de dirigir a vida intelectual, cultural e social de uma determinada sociedade por meio do consenso.

Gramsci contribui para o desenvolvimento e atualização de conceitos marxistas, apesar de não ter produzido uma obra geral no sentido

4 Antonio Gramsci ne fournit jamais une definition precise de l'hégémonie, susceptible d'étre valide une fois pour toutes (Hoare e Sperber, 2013, p. 95). 
acadêmico/científico. Sua obra é fragmentada, pelos mais diversos motivos, em especial porque passou longos períodos na prisão. Além disso, os textos e os fragmentos são definidos a contextos históricos específicos. Mas assumindo todo o cuidado com a fragmentação das ideias gramscianas, nada disso é empecilho para que suas formulações mais elucidativas sejam usadas em outros contextos.

Uma teórica que transplanta para outro espaço contemporâneo os conceitos de Antônio Gramsci é Gayatri Chakravorty Spivak. A professora de origem indiana vai elaborar uma questão central, com um pano de fundo gramsciano, sobre subalternidade e hegemonia em seu instigante trabalho Pode o subalterno falar?.

O livro é basicamente uma crítica de Spivak aos dois autores (Michel Foucault e Gilles Deleuze) que concordavam sobre uma possível "soberania do sujeito" sem questionar a posição subalterna que necessita de uma posição ideológica contra-hegemônica (Spivak, 2010, p. 30).

A discussão é profunda, mas o que interessa é recuperar neste momento um dos argumentos de Spivak (2010, pp. 31-35) usado para responder à pergunta sobre o espaço de fala do subalterno. Nesse contexto, entra a distinção entre vertreten (representar) e dasrtellen (re-presentar).

O termo vertreten está no sentido da política, do falar por procuração. Já o darstellen está no sentido da arte, do teatro, do atuar. Spivak (2010) mostra, durante todo o livro, que é possível representar e re-presentar. O problema está na forma que elas são colocadas. A transparência nem sempre revela qual representação o sujeito assume. Mas o fato é que, de forma geral, os subalternos não conseguem fazer a sua própria representação, e por esse motivo sempre são ouvidos na voz de um terceiro, que tem o poder de falar por ele ou de falar sobre ele, o poder do vertreten.

Revela-se, assim, a banalidade das listas produzidas pelos intelectuais de esquerda nas quais nomeiam subalternos politicamente perspicazes e capazes de autoconhecimento. Ao representá-los, os intelectuais representam a si mesmos como sendo transparentes (Spivak, 2010, p. 33). 
João do Rio não era nenhum intelectual político de esquerda. Neste artigo, considera-se que o jornalista apenas revelava a miséria e as mazelas cosmopolitas, com um interesse que chamava a atenção da burguesia: o de voyeur. Ele percorria os locais aonde ninguém queria ir, mas que despertavam a curiosidade de muitos sobre o desconhecido. Isso fazia o seu diferencial.

Mas o mais intrigante é que tudo era revelado por uma voz que não provém de um ambiente rico; apesar de transitar entre as diversas camadas da sociedade, ele mesmo pertencia às camadas subalternas.

Mulato, calvo, gordo e homossexual, a personagem João do Rio des-
colou-se de sua matriz biográfica (Paulo Barreto) e garantiu espaço
no inventário de seu tempo. Com seus fraques sempre verdes, sua
presença era indisfarçável e seu público jamais era neutro. [...] Paulo
Barreto morreu da mesma forma como viveu e escreveu. Rodeado
dos aparatos materiais, ideológicos e sociais da vida nas grandes
cidades, o autor fez do urbano seu mote único e inesgotável, e sua
própria imagem pública era uma alegoria do ethos da metrópole
(O’Donnell, 2008, pp. 14-15).

João do Rio/Paulo Barreto tinha acesso aos grupos subalternos e às camadas mais altas da sociedade; ele circulava "pelos espaços díspares e contraditórios da urbe carioca" " "foi, acima de tudo, um dândi, um intelectual elegante e refinado, que alcança prestígio junto à elite carioca nos momentos áureos da Belle Époque e a ela se mantém fiel" (Alves, 2009, p. 357).

Não se pode dizer que ele era bem aceito. Não só a concorrência por ter conseguido entrar na Academia Brasileira de Letras, mas também o homossexualismo, o faziam alvo de diversos escritores famosos. Entre eles, estava Emílio de Menezes, um poeta de sonetos satíricos.

Na primeira edição de 1962, o jornal semanal Novos Rumos recupera várias quadrinhas de Emílio de Menezes. Entre as mais perversas, uma se destaca:

Na previsão de próximos calores

a Academia que idolatra o frio

Não podendo comprar ventiladores

Abriu as portas para João do Rio (Menezes, 1962, p. 5). 
O poeta satiriza o frio no sentido de frescor, frescura. Título que João do Rio ganhou de seus rivais ao longo da carreira. $\mathrm{O}$ jornalista levava uma vida espalhafatosa e, de fato, provocava a ira de outros escritores, numa época em que se falava muito pouco sobre homossexualismo.

\section{Motivos e métodos}

A alma encantadora das ruas, terceira obra de João Rio (2007), é uma coletânea de reportagens/crônicas publicadas entre 1904 e 1907 no jornal Gazeta de Noticias e na revista Kosmos, originalmente reunidas na forma de livro em 1908. As histórias retratam a cosmópole carioca e se trata do livro mais conhecido de João do Rio.

Foi escolhido para análise devido à diversidade de ambientes e temas dentro da narrativa. Apesar de As Religiões no Rio, o primeiro livro do autor, trazer as primeiras reportagens in loco, "ao vivo" e em ambientes subalternos, este artigo parte do entendimento que a terceira obra apresenta melhor a sociedade da época.

Por outro lado, ao assumir a obra de João do Rio como uma etnografia das ruas do Rio de Janeiro no início do século XX, enfrentamo-nos com um texto etnográfico já pronto, feito da relação do autor com seus informantes, num trabalho de campo convencionalmente feito "ao vivo" (O’Donnell, 2008, p. 23).

Assim, para tentar responder às questões sobre a possibilidade de fala do subalterno e o sentido de cidadão nas obras escolhidas, será usado para a análise e tratamento dos conteúdos o software conhecido como Weft QDA. Segundo Gaskell (2011, pp. 86-88), as plataformas do tipo QDA (Qualitative Data Analyses) vêm apresentando resultados proveitosos em relação ao uso do computador. Entre as vantagens estão:

a) importar documentos de texto simples a partir de arquivos de texto ou PDF;

b) codificação de nível de personagem usando categorias organizadas em uma estrutura de árvore;

c) recuperação de texto codificado; 

d) estatísticas de codificação;
e) rápida pesquisa de texto livre;
f) codificação e pesquisas usando consultas booleanas (e, ou, não);
g) avaliar os padrões de codificação em vários documentos.

Gaskell (2011, pp. 87-88) lembra que os softwares fazem o trabalho do pesquisador ter mais precisão. Contudo, ele alerta que o "mito do computador" ainda está presente. A intenção aqui não é substituir as vantagens da ferramenta pela percepção do autor. O objetivo é facilitar o processo de análise, mas com prudência às vantagens tecnológicas.

Basicamente o software faz uma análise estatística do conteúdo. Ele permite uma análise quantitativa, numa seara qualitativa, e também dá a possibilidade de análise qualitativa do discurso. O programa permite separar trechos com quantidades de caracteres predeterminados, nos quais se encontrem palavras em comum.

Dessa forma, pode-se tanto fazer análise e contagem de palavras, como também separar trechos do texto, nos quais as mesmas palavras estão inseridas. Ou seja, as duas possibilidades proporcionam possibilidades para a análise de discurso e conteúdo.

\section{Categorias de análises}

As categorias foram eleitas de acordo com o próprio texto do João do Rio. Foram escolhidas palavras que se repetiam na obra. A codificação foi separada de acordo com os objetivos. As palavras serão organizadas em ordem decrescente, segundo sua repetição nos textos, e separadas em conformidade com o próprio programa Weft QDA.

Exemplo: Dentro da obra de João do Rio, que palavras aparecem e caracterizam a condição de subalterno? Miséria, pobreza, mendigo, operário entre outras. De forma semelhante, que termos se associam às camadas superiores, hegemônicas? Cidadão e cidadania podem ser percebidos como o quê? Desse modo, este artigo apresenta as seguintes categorias, que seguem uma lógica dentro da obra e dos objetivos propostos. 


\section{Tabela 1}

\section{Categorias em A Alma encantadora das ruas}

\begin{tabular}{|c|c|c|}
\hline \multicolumn{3}{|r|}{ Categorias de análises } \\
\hline \multicolumn{2}{|c|}{ Categorias } & Palavras que configuram as categorias \\
\hline 1 & Ambientes & $\begin{array}{l}\text { Rua, largo, cidade, bairro, avenida, botequim, confeitaria, açougue, hotel, fábrica, indústria, feira, } \\
\text { praça, prédio, beco, ruelas, favela, cafés, casa, sala, quarto, cortiço, estiva. }\end{array}$ \\
\hline 2 & Subalterno & $\begin{array}{l}\text { Pobre, miséria, mulher, negro, pobrezinho, humilde, coitado, infeliz, miserável, operário, trabalhador, } \\
\text { feio, bandido, gatuno, vagabundo, ociosos, ambulante, prostituta, rapariga, meretriz, anônimas, } \\
\text { escravo, malandro, injustiça, fome, doença, viciado, esmola, sofrer, abandono, turba, massa, mendigo, } \\
\text { assassino, crime, criminoso, pus, sangue, morte, morto, violência, sujo, classe popular, classe humilde, } \\
\text { popular, populaça, flanar, flâneur, ignorante, velho. }\end{array}$ \\
\hline 3 & Hegemônico & $\begin{array}{l}\text { Moderno, progresso, reis, indústria, industrial, comércio, rico, dinheiro, burguês, burguesa, acionista, } \\
\text { moeda, boêmia, dono, patrão, proprietário, imperador, mocinhos, césares, senhores feudais, chefes } \\
\text { de polícia, grupo restrito, notável, mercantilismo, celebridade, sábios, juiz, autoridade, Estado, } \\
\text { diplomata, monarquista, doutor, capital, presidente, deputado, políticos, marechal, governo, } \\
\text { administrador, prefeito, barão, homem de negócio, cavalheiro, médico, comércio, rainha, grão- } \\
\text { duques, gente chique, polícia, elegante. }\end{array}$ \\
\hline 4 & Cidadania & $\begin{array}{l}\text { Povo, nação, pátria, patriotismo, patriota, cidadão, cidadania, multidão, meeting, liberdade, leis, } \\
\text { justiça, saúde, educação, educar, higiene, higiênico, polícia, delegado, política, voto, direito, trabalho, } \\
\text { segurança, bonde, religião, emprego, sem emprego, nacional, cordão, carnaval, festa, imprensa, } \\
\text { expressão, escola, cidade, país, bairro, terra, Brasil, patriotadas, bandeira, brasileiros, Santos Dumont, } \\
\text { nacionalidade, independência, Revolução Francesa, eleição, urbs, alma urbana. }\end{array}$ \\
\hline 5 & $\begin{array}{c}\text { Pronomes } \\
\text { pessoais }\end{array}$ & Eu, tu, eles, elas, nós, vós, eles, elas. \\
\hline
\end{tabular}

Fonte: Os autores.

Cada uma das três categorias maiores (subalterno, hegemônico e cidadania) está representada por 50 palavras. O intuito é dar equilíbrio maior, já que são categorias comparativas. São palavras encontradas no próprio texto do jornalista. Já os pronomes são colocados na intenção de saber o espaço de fala do sujeito e também do outro.

\section{Análises}

As tabelas e os gráficos que vêm na sequência representam as dez palavras que mais aparecem no texto de João do Rio, dentro do universo $200 \mathrm{ca}$ racteres e respeitando cada categoria. Isso dá uma noção de interesse do jornalista em determinados contextos. Com exceção da Categoria 5, só aparecerão as dez palavras de maior destaque, que se repetem mais vezes no texto. Contudo, em outros momentos, a ausência e o número pequeno de repetições também serão considerados. 


\section{Tabela 2 \\ Categoria 1}

\begin{tabular}{|c|c|c|c|c|c|c|c|c|c|c|}
\hline Ambientes & Rua & Cidade & Casa & Largo & Sala & Praça & Beco & Bairro & Quarto & Praia \\
\hline Repetições & 126 & 76 & 61 & 24 & 18 & 15 & 14 & 11 & 10 & 9 \\
\hline
\end{tabular}

Fonte:Adaptado do software Weft QDA.

É evidente o interesse de João do Rio pela cidade conforme a tabela 1. No entanto, há também um olhar ampliado para o que acontece em ambientes internos, privados. $\mathrm{O}$ jornalista descreve a intimidade das pessoas, procura não só o que está aparente, mas também o que não pode ser visto.

Um momento que representa bem os locais da intimidade proibida, da atividade marginal, é quando João do Rio se passa por fornecedor de ópio. Ele e um amigo pedem para entrar numa casa de chineses viciados em droga, que ficava no Beco dos Ferreiros.

- Como se chama você? - Tchang... Afonso. - Quanto pode fumar de ópio? - Só fuma em casa... Um bocadinho só... faz mal! Quanto pode fumar? Duzentas gramas, pouquinho... Não tem dinheiro. Sinto náuseas e ao mesmo tempo uma nevrose de crime. A treva da sala torna-se lívida, com tons azulados. Há na escuridão uma nuvem de fumo e as bolinhas pardas, queimadas à chama das candeias, põem uma tontura na furna, dão-me a imperiosa vontade de apertar todos aqueles pescoços nus e exangues, pescoços viscosos de cadáver onde 0 veneno gota a gota dessora. $\mathrm{E}$ as caras continuam emplastradas pelo mesmo sorriso de susto e de súplica, multiplicado em quinze beiços amarelos, em quinze dentaduras nojentas, em quinze olhos de tormento! (Rio, 2007, p. 94).

Uma curiosidade sobre o texto de João do Rio é a riqueza de detalhes. Ele descreve os odores e as cores que compõem as cenas. O jornalista não só dá movimento e instantaneidade, mas também descreve um ambiente vivo de contrastes.

\section{Tabela 3 \\ Categoria 2}

\begin{tabular}{|l|c|c|c|c|c|c|c|c|c|c|}
\hline Subalterno & Pobre & Homem & Mulher & Crime & Miséria & Negro & Morte & Ambulante & Gatuno & Humilde \\
\hline Repetições & 74 & 68 & 67 & 43 & 33 & 25 & 21 & 20 & 19 & 18 \\
\hline
\end{tabular}

Fonte:Adaptado do software Weft QDA. 
Fica claro que a criminalidade e a miséria estão bem presentes na obra de João do Rio. Dentro da perspectiva do jornalista, a mulher sempre está em desvantagem. Nota-se que homens e mulheres são abordados de certa forma equiparada. Contudo, com o Weft QDA é possível separar os contextos nos quais as palavras aparecem: a mulher é vista pelo ângulo da sensualidade, religiosidade, mas também como vítima de agressão masculina, como criminosa de pequenos delitos, afogueadas, amantes, religiosas, mães, prostitutas, conversadeiras entre outras. No entanto, nunca em posição privilegiada.

Estela, mulatinha, vive com uma dama que se diz sua avó, na Rua Senador Eusébio. Às vezes fica até às dez horas da noite à porta da Central, esmolando. Nicota, moradora no Pedregulho, tem treze anos e perigosa viveza de olhar. A puberdade, a languidez dos membros rijos dão-lhe receitas grandes. É mandada pelo padrasto, um português chamado Jerônimo, que a industria. Explora a miséria no jardim de Eros, fazendo tudo quanto a não prejudica definitivamente, à porta dos quartéis, pelos bairros comerciais, ao escurecer (Rio, 2007, p. 172).

Os negros são os que perambulam, os criminosos, malandros, os que sobrevivem de acordo com a miséria. Num trecho a seguir é possível perceber o encontro das possibilidades do vulnerável, o encontro entre substantivos e adjetivos que apresentam o subalterno da prostituição e exploração infantil, é o ambiente de aprendizes de petizes, dos pequenos delitos, são: crianças, meninas exploradas e negras.

No mesmo texto, João do Rio (2007, pp. 138-142) descreve as "fulanitas do gozo", mulheres anônimas que vivem de migalhas da feira e dos desvios que a rua pode oferecer. São desconhecidas. Uma atende apenas por Jesuína, pois o sobrenome não interessa. Nesse caso, as mulheres são bonitas, porém pobres. Vivem a sonhar com as vitrines nas quais passam olhando durante todo o dia. Sonham com produtos de luxo que nunca poderão ter. Após consumirem com o olhar as montras, o que lhes restam são as pencas de filhos e os velhos que elas devem cuidar.

João do Rio investiga também o que não interessa à polícia, relata a feitiçaria, os pequenos golpes, a malandragem e a sobrevivência nas ruas. 
Nesse mundo diverso, o jornalista desvela uma sociedade complexa, que ele mesmo assume desta forma: "É preciso estudar a sociedade complicada e diversa” (Rio, 2007, p. 162).

\section{Tabela 4}

\section{Categorias 3 e 2}

\begin{tabular}{|c|c|c|c|}
\hline Hegemônico & Repetições & Repetições & Subalterno \\
\hline Dinheiro & 32 & 74 & Pobre \\
\hline Polícia & 22 & 68 & Homem \\
\hline Cavalheiro & 12 & 67 & Mulher \\
\hline Proprietário & 11 & 43 & Crime \\
\hline Elegante & 10 & 33 & Miséria \\
\hline Rico & 8 & 25 & Negro \\
\hline Comércio & 8 & 21 & Morte \\
\hline Celebridade & 7 & 20 & Ambulante \\
\hline Governo & 7 & 19 & Gatuno \\
\hline Autoridade & 7 & 18 & Humilde \\
\hline
\end{tabular}

Fonte: Adaptado do software Weft QDA.

A tabela 5 revela a discrepância entre o pobre e a autoridade. $\mathrm{Na}$ verdade, logo no começo do livro, o autor mostra que a elite não se mistura com os pobres, mesmo quando ficam sem dinheiro. Ou seja, ao falar sobre o subalterno, sobre os mais pobres, as repetições de palavras associadas à elite são muito menores, o que indica a percepção de mundos diversos e separados.

Eu conheci um elegante barão da monarquia, diplomata em perpétua disponibilidade, que a necessidade forçara a aceitar decerto proprietário 0 quarto de um cortiço da Rua Bom Jardim. [...] 0 barão sentia-se desesperado e resumira a vida num gozo único: sempre que podia, tomava 0 bonde de Botafogo, acendia um charuto, e ia por ali altivo, airoso, com a velha redingote abotoada, a "caramela" de cristal cintilante... Estava no seu bairro. Até parece, dizia ele, que as pedras me conhecem! (Rio, 2007, p. 37).

Confirma também que o universo dos textos do jornalista é a miséria. A palavra dinheiro é uma constante na obra, mas é muito mais a procura do pobre por dinheiro do que qualquer outra coisa. Isso fica mais claro quando 
os dados são cruzados. A tabela 6 representa melhor essa perspectiva. Notase que existe uma linha decrescente que vai do subalterno ao hegemônico.

\section{Tabela 5}

\section{Dez palavras mais usadas nas categorias 3 e 2}

\begin{tabular}{|c|c|c|c|c|c|c|c|c|c|c|}
\hline $\begin{array}{c}\text { Cruzamento } \\
\text { de dados }\end{array}$ & $\underset{0}{\frac{0}{6}}$ & 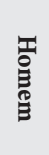 & 容 & : & 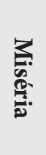 & $\begin{array}{l}\text { ్․ } \\
\text { E्ञ } \\
\text { : }\end{array}$ & $\frac{\overparen{D}}{\overline{\bar{D}}}$ & 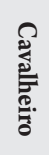 & 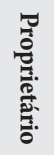 & 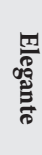 \\
\hline Pobre & 74 & 13 & 16 & 8 & 6 & 11 & 3 & 1 & 2 & 2 \\
\hline Homem & 13 & 68 & 12 & 10 & 4 & 4 & 4 & 3 & 2 & 2 \\
\hline Mulher & 16 & 12 & 67 & 11 & 6 & 2 & 2 & 2 & 1 & 2 \\
\hline Crime & 8 & 10 & 11 & 43 & 2 & 1 & 3 & 1 & 0 & 1 \\
\hline Miséria & 6 & 4 & 6 & 2 & 33 & 4 & 2 & 1 & 0 & 0 \\
\hline Dinheiro & 11 & 4 & 2 & 1 & 4 & 32 & 2 & 0 & 1 & 1 \\
\hline Polícia & 3 & 4 & 2 & 3 & 2 & 2 & 22 & 1 & 3 & 0 \\
\hline Cavalheiro & 1 & 3 & 2 & 1 & 1 & 0 & 1 & 12 & 0 & 1 \\
\hline Proprietário & 2 & 2 & 1 & 0 & 0 & 1 & 3 & 0 & 11 & 1 \\
\hline Elegante & 2 & 2 & 2 & 1 & 0 & 1 & 0 & 1 & 1 & 10 \\
\hline
\end{tabular}

Fonte: Adaptado do software Weft QDA.

A tabela 6 revela que João do Rio está muito mais interessado no mundo da pobreza do que propriamente no do crime. A bandidagem está presente na malandragem, nos pequenos golpes, nas mulheres vítimas e também criminosas. Contudo, o jornalista não relata apenas a vadiagem. Ele descreve ainda os vendedores de livros, os trabalhadores da estiva, os cocheiros, os tatuadores, entre outros.

É bom dizer algumas coisas que não se repetem com frequência e que chamam atenção. Por exemplo, a palavra feio (no masculino) aparece apenas em duas situações, sempre relacionada ao contexto do trabalhador. Primeiro surge no contexto de um cocheiro velho, conhecido de infância de Paulo Barreto. E a segunda mostra a distinção que faz entre indivíduos pertencentes a camadas distintas da hierarquia social.

Os operários vêm talvez mal-arranjados, com a lata do almoço presa ao dedo mínimo. Alguns vêm de tamancos. Como são feios os ope- 
rários ao lado dos mocinhos bonitos de ainda há pouco! Vão conversando uns com os outros, ou calados, metidos com o próprio eu (Rio, 2007, p. 138).

O’Donnell (2008, p. 50) lembra muito bem que, no início da gestão do prefeito Francisco Pereira Passos, foi instituída a "Liga contra o feio" e a "Liga da defesa estética". Ambas tinham o objetivo de transformar a cidade do Rio na cidade maravilhosa. A valorização do belo aparece, então, associada a uma questão mais ampla, de alcance social.

Outro elemento que aparece pouco é cidadão. O sentido da palavra não pode ser levado em consideração da mesma forma que é entendido na atualidade. Carvalho (2011, pp. 10-11) lembra que o conceito mais bem acabado de cidadão e de cidadania em categorias subdivididas somente foi desenvolvido por T. A. Marshall, em 1949, e refere-se ao desdobramento dos direitos em direitos civis, políticos e sociais. Cidadão pleno seria aquele que fosse titular dos três direitos. Incompletos os que possuíssem alguns direitos e não cidadão aqueles sem nenhum direito. Para Carvalho, esses direitos reportam-se à liberdade, propriedade, igualdade diante da lei, pensamento e manifestação, saúde, educação, participação na vida política e na distribuição da riqueza socialmente produzida. Assim, cidadania no sentido atual é algo desconhecido para João do Rio. A categoria 4, intitulada Cidadania, retrata os elementos que fazem referência ao cidadão.

\section{Tabela 6}

\section{Categoria 4}

\begin{tabular}{|c|c|c|c|c|c|c|c|c|c|c|}
\hline Cidadania & $\begin{array}{l}\text { ̊ } \\
\overline{\#} \\
\text { 馬 }\end{array}$ & مे & $\begin{array}{l}\ddot{\Xi} \\
\text { ̋̈ }\end{array}$ & $\begin{array}{l}\frac{\pi}{0} \\
\frac{0}{0} \\
0\end{array}$ & 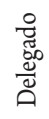 & 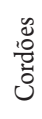 & 胥 & 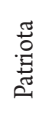 & $\begin{array}{l}\widetilde{\Xi} \\
\tilde{\Xi} \\
\tilde{Z} \\
z\end{array}$ & 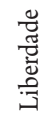 \\
\hline Repetições & 49 & 34 & 22 & 22 & 16 & 12 & 11 & 10 & 10 & 10 \\
\hline
\end{tabular}

Fonte: Adaptado do software Weft QDA.

No início vida cotidiana moderna, João do Rio contrasta a figura do cidadão com o povo. Existe um sentimento de um recente projeto republicano de desenvolvimento, de bons costumes, que não acompanhava as práticas do povo. $\mathrm{O}$ cidadão era aquele personagem honesto, de boa índole, 
boa praça que habitava a cidade. O povo é o resto e o cidadão é visto como vítima do outro, do desconhecido que por ele é revelado.

Judite, com oito anos, moradora à Rua da Lapa, andava com o pai pelo subúrbio, tocando realejo. 0 pai fingia-se de cego, e como um cidadão descobrisse a patifaria, é ela só quem esmola, atacando as senhoras, pedindo algum dinheiro para a mãe moribunda (Rio, 2007, p. 172).

A figura do cidadão aparece poucas vezes, porque João do Rio se apropria da estética da beleza pregada naquele momento. O jornalista mostra o povo, a turba, o "populacho", que varia entre o indivíduo subalterno que trabalha com extração de minérios, em jornadas de mais de dez horas, ou em pequenas profissões informais, mendigos, pequenos golpistas, presidiários. Revela ainda a reta final, a rua sem saída, a morte, na perspectiva de que o meio faz o homem.

João do Rio retrata a cidade dividida pelas profissões, camadas sociais e pelo horário do bonde, que denuncia a qual cada um faz parte. $\mathrm{O}$ bonde, símbolo da velocidade e da vida frenética moderna, transporta a divisão do trabalho.

Já passaram as professional beauties, cujos nomes os jornais citam; já voltaram da sua hora de costureiro ou de joalheiro as damas do alto tom; e os nomes condecorados da finança e os condes do Vaticano e os rapazes elegantes e os deliciosos vestidos claros airosamente ondulantes já se sumiram, levados pelos "autos", pelas parelhas fidalgas, pelos bondes burgueses. A rua tem de tudo isso uma vaga impressão, como se estivesse sob o domínio da alucinação, vendo passar um préstito que já passou. Há um hiato na feira das vaidades: sem literatos, sem poses, sem flirts. Passam apenas trabalhadores de volta da faina e operárias que mourejaram todo 0 dia (Rio, 2007, pp. 137-138).

O projeto da "República Velha” apenas disfarça a infinidade de contrastes que compõe a sociedade descrita pelo cronista. A participação política se limita ao processo eleitoral e à multidão que vota. $\mathrm{O}$ povo se torna nacional, quando chega o carnaval. É nos cordões carnavalescos que todos se misturam, mesmo contra vontade, quando o cidadão é arrastado pela multidão. 
O Estado é ausente e quando aparece está representado na figura da polícia. No outro lado está a liberdade, tanto no desejo dos detentos, como também na imprensa, que serve como meio de informação de camadas diversas. João do Rio (2007, p. 202) nota que os jornais estão presentes até nas prisões.

Um repórter é para essa gente inferior o poder independente, uma necessidade como a monarquia e o céu. Anunciar um repórter nas galerias é agitar loucamente os presos. Uns esticam papéis, provando inocência; outros bradam que as locais de jornais estavam erradas, outros escondem-se, receando ser conhecidos (Rio, 2007, p. 202).

Para Ribeiro (2004, p. 206), João do Rio significa a refronteirização do conceito de público dentro de novos ambientes. $\mathrm{O}$ cronista expandiu o jornalismo para locais inimagináveis que fogem dos $5 \%$ já mencionados, nos quais a produção e o consumo da informação estão nos mais diferentes recantos. Fazem parte de um ambiente urbano que abriga vendedores de panfletos analfabetos, mas que para se manterem informados se sentam ao lado de outros que não tiveram educação formal, conseguem ler.

Ao retomar a questão da possibilidade de fala do subalterno, importa saber como o autor se posiciona no texto. Pode o subalterno falar em $A$ alma encantadora das ruas?

\section{Tabela 7}

Categorias 5

\begin{tabular}{|c|c|c|c|c|c|c|}
\hline \multirow{2}{*}{ Pronomes Pessoais } & \multicolumn{3}{|c|}{ Primeira pessoa } & \multicolumn{4}{c|}{ Segunda e terceira pessoa } \\
\cline { 2 - 8 } & Eu & Nós & Ele/Eles & Ela/Elas & Tu & Vós \\
\hline Repetiç̃oes & 135 & 47 & 89 & 56 & 16 & 9 \\
\hline Soma & \multicolumn{2}{|c|}{182} & \multicolumn{4}{|c|}{170} \\
\hline
\end{tabular}

Fonte: Adaptado do software Weft QDA.

Nesse momento de transição entre jornalismo e literatura, João do Rio é mais narrador participante do que repórter. A reportagem in loco se faz no ambiente subalterno; no entanto, surge do ponto de vista jornalístico, no qual o "eu" está acima de outras pessoas em número, forma 
e gênero. $\mathrm{O}$ subalterno fala em segundo plano na realidade construída por João do Rio. Na soma, a primeira ainda supera a segunda e terceira pessoas.

Fui para outro e ofereci-Ihe uma moeda de prata. — Isso é para mim?

- É, mas se falares a verdade. - Ai! que falo, meu senhor... Tinha um olhar verde, perturbado, um olhar de vício secreto. - Há quanto tempo aqui? - Vai para dois anos (Rio, 2007, p. 152).

O dinheiro representa a tentativa desesperada de negociação pela verdade, em ambiente hostil, em que se encontravam capatazes que controlavam uma leva de mineradores livres, porém escravos das dívidas com as empresas para as quais trabalhavam. João do Rio era um corpo estranho que especulava muito, e $\mathrm{o}$ ato de oferecer aquele níquel não significa a garantia de verdade.

\section{Conclusão}

João do Rio não foi um líder das classes operárias e também não pretendia representar a posição de classe (subalterna, no caso). É importante dizer que os direitos trabalhistas serão conquistados, no Brasil, apenas a partir de Getúlio Vargas. A noção de classe para o jornalista é superficial e econômica. O que se encontra são relatos da vida moderna, da Belle Époque tropical e veloz, em contraste com a pobreza, seara propícia à reportagem in loco, em ambiente subalterno.

Pode-se concluir que dizer que João do Rio se comporta de forma egocêntrica, o "eu" que aparece de forma obcecante já percebido em Medina na década de 1980, é insuficiente para desqualificar o social em sua narrativa. $O$ interessante é saber que o jornalista nasce nas camadas subalternas e aprende a operar dentro dos padrões hegemônicos, como tantas outras pessoas. Ele é o próprio expoente híbrido que consegue transitar entre as extremidades da sociedade. $\mathrm{O}$ jornalista revela o "ao vivo" cosmopolita, mais do que isso, o intelectual representa a si mesmo, mesmo quando identifica sua condição comparada às "camadas proletárias".

Nesse caso, a presença do subalterno na escrita de João do Rio se dá a partir de constatações realizadas pelo autor: ele é revelado como explo- 
rado, pratica crimes, sujo, feio e sem meios de expressão. Desorganizado, pode até ter acesso a algum tipo de informação, mas, mesmo diante das perguntas feitas pelo jornalista, seu espaço de fala, sua disposição e possibilidade para falar são mínimos.

Ao mergulhar no mundo marginal, miserável, ele não "fala por”, não representa o subalterno. João do Rio/Paulo Barreto apresenta o que vê nas ruas, no qual o "eu” está mais presente do que o "outro". Isso significa que o que está em evidência é o seu próprio ponto de vista. Parece não haver a intenção de falar por, reivindicar, nem mesmo se indignar, simplesmente relatar. E retratar. $\mathrm{O}$ que não diminui o valor dos temas e das formas de suas narrativas, mesmo porque a noção de cidadão e de cidadania tal como se concebe atualmente não parecia fazer parte das inquietações ou demandas sociais daquela época. Vale lembrar que Carvalho (2011, p. 83) afirma que até 1930 não existiu sentimento nacional e muito menos povo organizado. No entanto, existe sim uma certa grandeza em tornar pública a condição de vida da maioria da população do Rio de Janeiro no começo do século XX.

\section{Referências}

Alves, R. C. (2009). "Entre o cristal e a chama: João do Rio e as leituras do urbano”. Revista Estudos Linguísticos, 38, 395-409.

Carvalho, J. M. (2011). Cidadania no Brasil. Rio de Janeiro: Civilização Brasileira.

Gaskell, G. (2011). Entrevistas individuais e grupais. Em: M. W. Bauer; G. Gaskell (Orgs.), Pesquisa qualitativa com texto, imagem e som: um manual prático (pp. 64-89). Petrópolis: Vozes.

Gramsci, A. (2001). Cadernos do cárcere: Os intelectuais. O princípio educativo. Jornalismo. $2^{\text {a }}$ ed. Rio de Janeiro: Civilização Brasileira.

Hoare, G., Sperber N. (2013). Introduction à Antonio Gramsci. Paris: La Découverte, coll. Repères. 
Medina, C. (1988). Notícia: um produto à venda. $2^{\text {a }}$ edição. São Paulo: Summus.

Menezes, E. (1962). Jornal Novos Rumos. $1^{\text {a }}$ edição. Rio de Janeiro.

O’Donnell, J. (2008). De Olho na Rua: A Cidade de João do Rio. Rio de Janeiro: Jorge Zahar.

Ribeiro, L. M. (2004). Imprensa e Espaço Público: A institucionalização do jornalismo no Brasil (1808-1964). Rio de Janeiros: E-papers.

Rio, J. D. (2007). A alma encantadora das ruas. São Paulo: Martim Claret.

Rio, J. D. (1994). O momento literário. Rio de Janeiro: Fundação Biblioteca Nacional: Depto. Nacional do Livro.

Rio, J. D. (1904). A fome negra. Em: Gazeta de Noticias. Ed. 174, de 22 de junho de 1904, Rio de Janeiro.

Spivak, G. C. (2010). Pode o subalterno falar? Belo Horizonte: Editora da UFMG.

Veríssimo, J. (1915). História da literatura brasileira. Rio de Janeiro: Fundação Biblioteca Nacional: Depto. Nacional do Livro.

Veríssimo, J. (1900). Livro do Centenário (1500-1900). Secção IV. Publicado sob os auspícios da Associação do Quarto Centenário do Descobrimento do Brasil. Rio de Janeiro: Imprensa Nacional. 